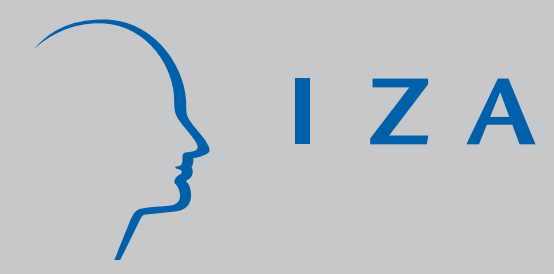

IZA DP No. 3224

Wages, Rents and Heterogeneous Moving Costs

Douglas J . Krupka

Kwame Donaldson

December 2007 


\title{
Wages, Rents and Heterogeneous Moving Costs
}

\author{
Douglas J. Krupka \\ $I Z A$ \\ Kwame Donaldson \\ Georgia State University
}

Discussion Paper No. 3224

December 2007

\author{
IZA \\ P.O. Box 7240 \\ 53072 Bonn \\ Germany \\ Phone: +49-228-3894-0 \\ Fax: +49-228-3894-180 \\ E-mail: iza@iza.org
}

\begin{abstract}
Any opinions expressed here are those of the author(s) and not those of the institute. Research disseminated by IZA may include views on policy, but the institute itself takes no institutional policy positions.

The Institute for the Study of Labor (IZA) in Bonn is a local and virtual international research center and a place of communication between science, politics and business. IZA is an independent nonprofit company supported by Deutsche Post World Net. The center is associated with the University of Bonn and offers a stimulating research environment through its research networks, research support, and visitors and doctoral programs. IZA engages in (i) original and internationally competitive research in all fields of labor economics, (ii) development of policy concepts, and (iii) dissemination of research results and concepts to the interested public.
\end{abstract}

IZA Discussion Papers often represent preliminary work and are circulated to encourage discussion. Citation of such a paper should account for its provisional character. A revised version may be available directly from the author. 


\section{ABSTRACT \\ Wages, Rents and Heterogeneous Moving Costs}

The model of compensating differentials in regional labor markets was developed by Roback (1982). The model interprets regional differences in constant quality wages and rents as compensating firms and residents for inter-regional differences in amenities. The model assumes that the costs of relocating to a new city are zero. The results hold in the presence of moving costs for the marginal migrant. This paper extends the Roback model to allow for moving costs which vary among a city's residents and businesses. This modification of the model generates new interpretations of regional differences in rents and (to a lesser extent) wages. The importance of amenities is retained, but housing supply becomes the main other determinant of regional rents. Housing supply was for the most part ignored in the literature following on Roback's initial insight. The new perspective also provides a bridge between the neo-classical perspective implicit in Roback's approach and the newer literature on agglomeration economies.

JEL Classification: R12, R13, R23, R31, J31

Keywords: compensating differentials, quality of life, housing supply, amenities, capitalization

Corresponding author:

Douglas J. Krupka

IZA

P.O. Box 7240

D-53072 Bonn

Germany

E-mail: dkrupka@iza.org

\footnotetext{
* This research has benefited from helpful comments from David Sjoquist, Douglas Noonan (who never believed), Geoffrey Turnbull, Uwe Sunde, and participants at the Georgia State University UREE Colloquium, and the IZA Brown Bag Seminar. Errors are nonetheless not their fault.
} 


\section{Introduction}

The formalization of the idea that area differences in wages and rents compensate people and businesses for local differences in desirable local amenities is attributable to Jennifer Roback (1982). This important formalization built on Sherwin Rosen’s (1974) seminal analysis of markets for bundled characteristics. An important difference between the two models is the use of a representative consumer (and firm) in Roback's model, as opposed to a focus on heterogeneity in preference and cost functions among firms and people in Rosen's paper. The Roback model also assumed for simplicity that moving costs are well approximated by zero. The addition of migration costs and heterogeneity was not seen as a major problem, as all the results of the model would still hold for the marginal migrant, defined as a person with zero migration costs.

In this paper, we loosen these two assumptions simultaneously, and show this change in the model modifies the interpretation of inter-city differences in wages and rents considerably. Intuitively, the presence of heterogeneous moving costs implies that at any combination of rents and wages, some people and businesses will be willing to locate in a city, given its amenity level. For the local labor market to be in equilibrium, an appropriate amount of residents and businesses must wish to locate in a city. ${ }^{1}$ The quantity side of regional equilibrium is something mostly ignored by Roback and the literature that followed her. For any given amenity level, there are a set of points in rentwage space that will satisfy local labor market equilibrium. However, this set of points includes a continuum of possible rents, populations and possibly wages. We show that

\footnotetext{
${ }^{1}$ Throughout the paper, we will use the term "city” in the urban economic sense. This term is approximated in the census data with urban areas or metropolitan statistical areas. We choose to use city because this is the concept the other terms approximate, and because it is shorter and sounds better.
} 
for any given amenity level, population, rents and wages are actually set by the local supply of housing.

This paper thus makes two significant contributions. First, the importance of housing supply in the presence of heterogeneous costs to migration changes the interpretation of coefficients in regressions of rents on local area characteristics. We show that in such a context, amenities that restrict housing supply will appear more "valuable" than amenities that do not. Thus, in terms of computing local quality of life (QOL) indices, areas with amenities that also restrict supply (such as coasts, steep mountains, national parks, etc.) will appear more attractive than areas with amenities that do not (such as climate and cultural amenities).

A second contribution of the paper is that it allows the Rosen-Roback model to be related more closely with the newer literature on agglomeration. With the model advanced in this paper, the very strong positive correlation among rents, wages and city population in the cross section can be interpreted as implying that larger cities are primarily driven by productive amenities. While this result is not too surprising, the incorporation of population in the analysis (which was missing in the QOL literature) allows for analysis of how population, rents, wages and amenities interact when greater populations of firms and workers leads to higher productivity, as has been hypothesized in many papers for a variety of reasons.

The rest of the paper is organized as follows. Section I outlines the RosenRoback model. Section II incorporates heterogeneous moving costs, and shows how in their presence local area housing supply is the most important determinant of rents. Wages are much more passive in this analysis. Section III discusses the model's 
implications for the QOL literature, then sketches out how the new model provides a bridge between the neoclassical, Rosen-Roback model and the new agglomeration literature. A final section concludes with some comments on the empirical content of the model, and some further rumination on the Rosen-Roback model.

\section{The Rosen-Roback model.}

Roback (1982) envisions a world where all people and business are the same. A firm is characterized by a cost function, which through profit maximization becomes a profit function that depends on local wages, rents and local attributes, or amenities. Costless migration implies that firms will relocate to new cities if they can earn higher profits there. In equilibrium, then, it must be the case that economic profits (profits in the city in question minus profits available elsewhere) must equal zero:

1) $\quad \pi(w, r ; A)-\underline{\pi}=0$.

In equation $1, \underline{\pi}$ represents the profits available to the firm in every other location. Similarly, people in the Roback model have preferences, which after utility maximization generate an indirect utility function which also depends on wages, rents and amenities. Amenities are defined to be goods for people, although the same assumption is not made for firms. Amenities can either be productive (profit enhancing) or unproductive (profit reducing). Costless migration across cities implies that the utility available in any city be identical to the utility available in any other location:

2) $\quad v(r, w ; A)-\underline{v}=0$,

where $\underline{v}$ is the utility available to a resident in every other location. As the discussion above makes clear $\pi_{r}<0, \pi_{w}<0$ and $v_{r}<0, v_{w}>0, v_{A}>0$ while $\pi_{A}$ is indeterminate in 
sign. Equations 1 and 2 implicitly define $\Pi$ and $V$, which are indifference curves for firms and people in rent-wage-amenity space. Figure 1 shows the equilibrium condition as usually represented. For a given level of amenities, rents and wages in a city are determined by the condition that firms and residents are indifferent between the city and all other cities, and that rents and wages are the same for firms and residents.

Within this framework, the effect of amenities on rents and wages are derived by taking the derivative of the equilibrium price and wages, as implicitly defined by the equality of $\Pi$ and $V$. Equations 3 and 4 show these derivatives and sign them for a productive amenity.

3)

$$
\frac{\partial r}{\partial A}=\frac{\left(\frac{\Pi_{A}}{\Pi_{w}}-\frac{V_{A}}{V_{w}}\right)}{\left(\frac{V_{r}}{V_{w}}-\frac{\Pi_{r}}{\Pi_{w}}\right)}>0 .
$$

4) $\frac{\partial w}{\partial A}=\frac{\left(\frac{\Pi_{A}}{\Pi_{r}}-\frac{V_{A}}{V_{r}}\right)}{\left(\frac{V_{w}}{V_{r}}-\frac{\Pi_{w}}{\Pi_{r}}\right)} \geq 0$.

These derivatives are also available from the manipulation of the indifference curves in Figure 1, as shown in Figure 2.

These results are important, because they provide a theoretical grounding for the use of the partial correlation of rents and wages with city characteristics as weights in constructing QOL indices, as was done by Roback and many later authors. ${ }^{2}$ Under the model's assumptions, the regression coefficients that these equations represent are appropriate measures of the value of the amenities because they incorporate only the

\footnotetext{
${ }^{2}$ See Gyourko et al. (1997) for a review of this literature.
} 
effects on utility and profits, and because they incorporate the preferences of both firms and residents.

\section{Heterogeneous moving costs}

While the model offers powerful insight into the processes that set regional wages and housing costs, it is perhaps too persuasive. There has been little research into the effects on the model of firm and worker heterogeneity and moving costs. Heterogeneity has generally been dealt with in a footnote noting that in its presence, the results hold for the marginal migrant. This marks a major departure from the original hedonic model of Rosen (1974), where the entire point is arguably to show the possibility of efficient sorting of buyers and sellers. The possibility of migration costs preventing the equilibrium described above was seen as making small deviations from equilibrium values possible, but has not been seen as either theoretically or empirically interesting.

We make one minor addition to the Roback model. Firms and residents are still assumed to be identical in their preference or cost functions, except for an idiosyncratic component representing costs of moving away from their current location. Equations 1 and 2 are thus rewritten as equations 5 and 6 :

5) $\quad \pi(w, r ; A)-\underline{\pi}+=\psi_{j} \square F(\cdot)$

6) $\quad v(r, w ; A)-\underline{v}=\varphi_{i} \square G(\cdot)$.

This change means that, for any given location (or, equivalently, any given level of amenities), firms and residents have identical preferences for wages, rents and amenities in general, but have idiosyncratic attachment to the location (moving costs). Because their preferences for wages, rents and amenities are the same, the idea of the $\underline{\pi}$ and $\underline{v}$ is 
still valid. This means we cannot address the sorting aspect of location choice as well as Rosen does. However, it simplifies the analysis.

The idiosyncratic attachments to a city could arise for a number of reasons. For people, investments in social ties, location specific human capital investments (as in Krupka (2007)), a sentimental and unreasoning fear of change, uncertainty about other cities or a difficult-to-replace job in the current city (such as an academic position) could all increase migration costs. From the perspective of the firm, large investments in fixed capital, adaptation to local business norms or the use of locally concentrated distribution networks, as well as the personal interests of the firm's decision makers would generate similar attachment to the current location. In both cases, a purely idiosyncratic taste for the area could also exist. These attachments will vary across individuals. We find these assumptions so descriptively obvious as not to warrant further elaboration. ${ }^{3}$

Equations 5 and 6 imply that the indifference curves used in figures 1 and 2 represent the preferences (or costs) of only one person (or firm). For any given amenity level, rent-wage space will be characterized by a field of $V$ and $\Pi$ curves, each representing a different person or firm. In general, for any given amenity level, indifference curves more to the left will be consistent with higher populations of firms and residents (because rents are lower for any given wage level), while indifference curves to the right will be associated with fewer residents willing to live in the city at those rent-wage combinations. If population is modeled as continuous, this set of indifferences curves could be thought of as two surfaces in rent-wage-population space sloping up as one moves away from the wage-axis.

\footnotetext{
${ }^{3}$ Tabuchi and Thisse (2002) embed such heterogeneity in a core-periphery model and show that the heterogeneity is a strong force for dispersion.
} 
While any rent-wage combination will be an equilibrium for some given combination of residential and commercial populations, only a subset of them will satisfy local labor market equilibrium, where the quantity of jobs equals the number of workers. That is, the city's economy will not be in equilibrium unless an additional condition holds:

7) $\quad G(v(r, w ; A))=F(\pi(r, w ; A))$,

where $F($.$) and G($.$) represents the \mathrm{CDF}$ of the gains to migration for firms and individuals, respectively. Equation 7 requires that the number of jobs be equal to the number of workers, ${ }^{4}$ and implicitly defines wages as a function of rents and amenities. Figure 4 highlights the set of points in rent-wage space where labor market equilibrium is achieved. This set of points could also be thought of as the intersection of the two surfaces described above.

The labor market equilibrium line in Figure 4 does two things. First, given an amenity level and the distribution of firms' and residents' idiosyncratic moving costs, the line defines wage as a function of rents. More broadly we will describe $w=w(r ; A)$. In Figure $4, w(r ; A)$ is drawn as a straight line with the mildest of positive slopes. In general, the slope and curvature or $w(r ; A)$ will depend on the $G$ and $F$ distributions and the relative importance of rents in the $v($.$) and \pi($.$) functions. If firms are more$ homogenous or are effected more by changes in rents, $w_{r}$ tends to be positive, while it tends towards negative if residents are more homogenous or are more affected by changes in rents.

\footnotetext{
${ }^{4}$ To keep things simple, we assume that each resident works and each firm hires one worker. Relaxing this assumption does not produce major changes in the model.
} 
The labor market equilibrium line also describes the level of population (of both firms and residents) in the city, which will also depend on rents and amenities. We call this relationship $\Omega(r ; A)$. It is clear from the above that $\Omega_{r}<0$, because higher rents will make a city less attractive for any given level of amenities. $\Omega(r ; A)$ will be important later when we close the model. It is the presence of $\Omega(r ; A)$ that begins to set the current model apart from the classic Roback formulation, which neglected population levels for the most part. We consider this addition to be highly desirable, as it certainly says something about the attractiveness of a location if more people live in it. If there is a small town somewhere in Colorado with wages and rents similar to those in San Francisco, the additional information that only hundreds of people live in the small town while millions live in San Francisco is information which to us seems relevant in terms of understanding the nature of the amenities in the two locations.

While the effects of rents on wages and population are relatively easy to derive, the effects of amenities are somewhat more muddled by the typology of amenities. We classify amenities in three categories: productive, nonproductive and unproductive. ${ }^{5}$ Productive amenities increase utility and profits; nonproductive amenities increase utility but do not affect profits, and unproductive amenities increase utility but decrease profits. In general, the effects of these kinds of amenities map directly onto the results from the standard Roback model, except that it does not yet make sense to talk about the effect of amenities on rents, since we have not yet derived equilibrium rents. Holding rents constant, productive amenities will increase population but have an ambiguous effect on wages. Nonproductive amenities will have a positive effect on population and a negative effect on wages. Unproductive amenities will have a negative effect on wages and an

\footnotetext{
${ }^{5}$ This $2^{\text {nd }}$ term is new, and we are very open to better ones.
} 
ambiguous effect on population. These results follow from equation 7 and from plugging $w(r ; A)$ into $G(r, w ; A)$.

For the partial effects above, it was necessary to hold rents constant because assuming labor market equilibrium in equation 7 did not actually close the model. For any distribution of moving costs and any level of amenities, there is a continuum of possible rent-wage-population combinations. To close the model, we must also assume that the local housing market is also in equilibrium. Equation 8 defines this condition:

8) $\quad S(r ; C)=\Omega(r ; A) D(r, w(r ; A))$.

In equation 8, we have introduced the housing supply function, which depends upon rents (positively, so that $S_{r}>0$ ) and other cost factors (so that $S_{C}<0$ ). The demand for housing depends on $\Omega$, or population, and the per-capita demand for housing, $D$, which depends on rents and wages. The final link in the equalities reinterprets demand as depending on rents and amenities, since wage is a function of rents and amenities for any given distribution of moving costs. Although $w_{r}$ is ambiguous of sign and $D_{w}$ is likely positive, we will assume that $D_{r}+D_{w} w_{r}<0$, so that the law of demand holds. If $w_{r}$ were positive, it would be technically possible for per capita demand for land to increase as rents increased.

Using equation 8 to implicitly define rents as a function of amenities and cost shifters, we can derive the effect of increasing amenities on local rents.

9) $\frac{\partial r}{\partial A}=\frac{\Omega_{A} D+\Omega D_{w} w_{A}}{S_{r}-\Omega_{r} D-\Omega\left(D_{r}+D_{w} w_{r}\right)}$.

This amenity effect bears little resemblance to the effect as derived in section I of this paper reproducing the Roback capitalization result (equation 3). This underscores just how much the addition of heterogeneous moving costs affects the model. The Roback 
“open city" results can be approximated by allowing $\Omega_{A}$ and $\Omega_{r}$ to approach positive and negative infinity, respectively. ${ }^{6}$ One interesting factor in equation 9 is the $S_{r}$ term in the numerator. As this term approaches infinity (as housing is supplied more elastically) the rent effect of amenities approaches zero. This is a formulization of a a result sduggested casually in the conclusion of Glaeser et al. (2006), which is another paper stressing the importance of housing supply in the setting of city rents.

An important result arising from equation equation 9 is that its sign is actually ambiguous for any kind of amenity. If the amenity in question is productive, the first term in the numerator is positive but the second term is ambiguous. If the amenity is nonproductive, the first term is unambiguously positive while the second term is unambiguously negative. Finally, in the case of an unproductive amenity (which reduces profits but increases utility), the first term in the numerator is ambiguous while the second term is negative. The denominator is always positive. Because wages are a deterministic function of rents and amenities, the ambiguity in these amenity effects on rents translates over to the amenity's effects on wages as well.

While ambiguous results are generally not considered as important as ones we can sign a priori, we think the ambiguity of equation 9 is an important result in its own right. ${ }^{7}$ It underscores that in the presence of heterogeneous moving costs - which certainly exist in the world which generates our data - we know much less about the effects of amenities on rents and wages than the Roback open-city formulation suggests. Furthermore, the importance of housing supply both in the setting of equilibrium rents (and thus wages),

\footnotetext{
${ }^{6}$ Taking this limit and rearranging terms confirms that the Roback result is a special case of the present model.

${ }^{7}$ Bloomquist et al. (1988) generate ambiguous effects by assuming that population (set as described above) has an ambiguous productivity or congestion effect after Tolley (1974).
} 
and in equation 9 is new. While Glaeser et al. (2005), Glaeser and Gyourko (2005), and Gyourko et al. (2006) have been moving towards this conclusion from other directions, the above frames the importance of housing supply directly in a compensating differentials model. What is important about equation 9 is not so much that it is ambiguous of sign, but that it includes several non-preference factors, such as housing supply, housing demand and the homogeneity of residents and firms (through the $\Omega$ terms). This is an important departure from the Roback amenity effects, which depend only on preference and profit parameters. This difference raises questions about the interpretability of the assumed hedonic prices derived from hedonic regressions. If these coefficients reflect elasticities of housing demand and supply and the distribution of moving costs among firms and people as well as the effects of amenities on utility and profits, how appropriate are they as weights in a QOL index? The following section makes two extensions of the model that, we think, further underscore its significance either empirically or theoretically.

\section{Some Implications.}

Driving the sign of a partial derivative to ambiguity is not a constructive contribution. In some sense, the simplification of a model is what allows us to get explicit signs in our theoretical relationships, and is the entire point of theory. We believe the teasing out of the importance of moving costs and amenity capitalization is an important next step in our understanding of cities' interaction and the workings of inter-city labor markets. However, there are other implications of the model which we address here. 


\section{Cost shifters and QOL indices}

The importance of housing supply in equation 9 is one of its contrasts with equation 3. The traditional Roback formulization of the effect of amenities on rents did not include housing supply factors because with costless migration (at least for the marginal migrant), cities with low amenities could not support higher rents because of local housing supply (cost) differences. To the extent that such differences increased rents, they would cause out-migration, thus lowering rents back to the level the local amenities made feasible. When migration costs are heterogeneous, however, cost-related rent increases can increase rents locally. While this will cause some people to move away (those with the lowest moving costs), some people will be willing to accept the higher housing costs in order to continue to capitalize on their local attachments. This result is easily shown by simply taking the derivative of the implicit rent function with respect to the cost term:

10) $\frac{\partial r}{\partial C}=\frac{-S_{C}}{S_{r}-\Omega_{r} \delta-\Omega \delta_{r}}>0$.

Given the above discussion, equation 10 is not at all surprising, although it bears emphasis that this result was simply unavailable in the Roback framework. The Roback result on local housing costs can be reproduced in this context by allowing $\Omega_{r}$ to approach negative infinity. This drives the denominator towards positive infinity, and the derivative as a whole to zero. Thus, with regard to the effect of housing costs on rents, the difference between our model and the Roback model arises from a difference in our assumption on the rent-elasticity of city population. Roback implicitly assumes this elasticity is negative infinity, we assume it is something larger than that. 
While equation 10 is not too surprising, a more important result is available if we allow for the existence of some amenities that affect the cost of land or of construction. There are many reasons why amenities may cause land to be more costly. For instance, in the canonical model of the monocentric city, high agricultural yields increase the opportunity cost of land city-wide. Such high agricultural yields could be the result of favorable climate. Rough terrain or large swaths of undevelopable area (such as water or national parks) could also increase the cost of land in a city by making land scarce or forcing longer commutes over or around these obstacles. Gyourko and Saiz (2006) show that topography also appears to have a positive direct effect on construction costs. As such features also offer considerable scenic and recreational value (are amenities) and sometimes increase profits (through shipping on coasts or mining in mountains) these features have two effects on local rents. First they may increase them because of their value as amenities. Second, they will increase rents through their effect on land or construction costs in the metro area. Other factors that could have similar effects (through both amenity and cost effects) would include the risk of natural disaster or regulations restricting development such as a binding urban growth boundary or reactionary zoning (Glaeser et al. (2005)).

The effects on rents of such supply-restricting amenities will be different from those that do not restrict supply, as can be seen in equation 11 .

11) $\frac{\partial r}{\partial A}=-\frac{S_{C} C_{A}-\Omega_{A} \delta-\Omega \delta_{A}}{S_{r}-\Omega_{r} \delta-\Omega \delta_{r}}$.

Equation 11 differs from equation 9 in that the term $S_{C} C_{A}$ has been added. This term represents the amenity's effect on the supply function through the cost term. What is somewhat troubling is that most natural amenities that leap to mind - coasts, mountains, 
parks - either restrict developable land or increase the cost of development. On the other hand, most cultural amenities have no supply effect. Equation 11 tells us that such cultural amenities will appear to be less important in the rental equation of a cross-city hedonic model than natural amenities that restrict housing supply. While equation 11 is still ambiguous for every kind of amenity, it is unambiguously greater when the amenity causes greater supply restrictions. ${ }^{8}$

The existence of this change in the effects of amenities on rents (and thus wages) is troubling because the QOL literature uses the effects of amenities on rents and wages as weights in the construction of all-encompassing QOL indices. Roback's beautifully argued theory leads us to believe that in estimating such weights, we are estimating equation 3 in the rent equation. However, heterogeneous moving costs imply that in fact we are estimating equation 9. While equation 9 may still be defensible as a weight in such an index, the situation is actually worse. For some amenities we are estimating equation 9, while for other, supply-restricting amenities, we are estimating equation 11. The net effect of this is that QOL indices will tend to overemphasize the value of supplyrestricting amenities relative to supply-neutral amenities, and thus rank areas with high levels of supply-restricting amenities higher in quality of life indices than areas specializing in more supply-neutral amenities. Even approaches which avoid the direct estimation of equation 11 (as in Kahn (1995) and Cragg and Kahn (1997)) will be affected by this supply-restricting effect because the lower supply of housing in some areas will be pushing rents up, making them look more attractive. It is unlikely that this bias will be corrected for with a cross-city wage hedonic because the wage effect of amenities is partly determined by the affect of amenities on wages through rents. Given

\footnotetext{
${ }^{8}$ This result could be confirmed by taking the derivative of equation 11 with respect to $C_{A}$.
} 
the ambiguous sign of the effect of rents on wages, it is as likely that the wage equation will exacerbate the bias as reduce it.

We are not the first to suggest that coefficients from the cross-city hedonic might be biased. Gyourko et al (1991) make a similar point with regard to local public finance issues. However, the bias we highlight here is perhaps more vexing because, empirically, correcting for this tendency will be extremely difficult. As we do not observe the value people and businesses place on certain characteristics, or the level and patterns of development that would have occurred in the absence of the supply-restricting features, it will be very difficult to determine how much supply has been restricted in a given urban area and how much rents have responded to that supply restriction, as opposed to the utility- and/or profit-enhancing aspects of the features restricting supply. However, without making such a distinction, it is hard to imagine how the coefficients in a crosscity hedonic would be appropriate in assigning weights to area characteristics. Such coefficients may be reflecting the high average moving costs of an area's population as much as the great value the citizens place on their local characteristics.

\section{Compensating differentials and agglomeration.}

An objection to the model above is that it derives a negative relationship between rents and city population, and an indeterminate relationship between wages and rents. These results do not square with the strong correlation amongst wages, rents and city population as noted by Glaeser and Maré (2001). This apparent inconsistency is resolved by recalling that the negative relationship between rents and population and the ambiguous 
relationship between wages and rents holds only when the levels of amenities are held constant.

Of course, amenities differ across cities, so the partial relationship among population, rents and wages with amenities held constant - while important for our analytical results - is not of much use empirically. The positive correlation between rents, wages and population suggests the importance of productive amenities with much greater effects on firm costs than on individuals' utility. One might call these firm or business amenities. $^{9}$ In the model above, such non-utility enhancing amenities increase the attractiveness of a location for businesses but not for residents. This drives both population and wages higher for any given level of rents. The higher population and higher wages imply higher demand for housing in the city in question, and thus higher rents. Thus if sites differ in the amount of this firm amenity, even if housing supply is the same across sites, the higher firm amenity sites could have higher populations, rents and wages in equilibrium.

While the above rationalizes the cross-sectional pattern in wages, rents and population, it does little in the way of explaining the origin of the firm amenity. If these firm amenities exist as features of the landscape, then we call them "natural advantage." Such fixed characteristics would, in the long run, lead to the higher wage, rent and population levels, but in equilibrium should not affect growth in these variables. On the other hand, if these firm advantages arise endogenously as a product of larger population, we call them agglomeration or urbanization economies, and we employ a very different

\footnotetext{
${ }^{9}$ We make the distinction between firm amenities and productive amenities because amenities as usually treated are assumed to increase utility, while amenities are described as productive or unproductive depending on their effect on profits. A firm amenity would be assumed to benefit profits and could be characterized further by distinguishing between firm amenities that enhance or detract from utility.
} 
set of theoretical tools in understanding them. Under certain assumptions, these endogenously generated firm amenities could induce continual growth divergence between large and small cities.

Interest in agglomeration economies has been increasing since Krugman's seminal 1991 Journal of Political Economy piece synthesized many older strands from the regional science literature to generate a micro-theory general equilibrium model that exhibited strong divergence and several interesting dynamic possibilities. Ottaviano and Thisse (2004) offer a review of the substantial theoretical literature that followed. Other authors have offered other avenues from which similar dynamics might arise. ${ }^{10}$ It has been difficult to assess the implications of this literature on the more neoclassical regional literature that follows Roback partly because Roback's model is mute on the scale of the city. By bringing city size into the analysis, the assumption of heterogeneous moving costs allows for a connection between the QOL literature and the newer agglomeration literature because amenities can be produced endogenously.

We believe this framework is attractive in that it is flexible enough to extend to additional analysis, which we do not pursue in this more limited paper. For instance, Roback, most or the agglomeration literature and this paper all assume perfectly functioning labor markets. This model is flexible enough to add labor market imperfections and/or dynamic labor market adjustments with local unemployment as an output. Such a dynamic extension of this static model could shed light on the cyclicality of employment, wages and rents, and how that cyclicality may (or may not) be conditioned by agglomeration externalities or amenities.

\footnotetext{
10 Glaeser (1999), Berry and Glaeser (2005) and Helseley and Strange (1990) are a few. Also see Duranton and Puga (2004) for a review of some of the more current theories.
} 
A more dynamic frame for the model could also yield insight into the longer-term fates of economic regions. While most productive amenities will increase rent, some will favor businesses more than others. Highly firm-oriented amenities will tend to increase rent and wage both, while more resident-oriented amenities will tend to increase rent alone. Differences in these kinds of amenities (football stadiums versus stock markets) would thus exhibit themselves in different relative changes in rents and wages as population increases. If one views the historical development of a city as the slow drawing out of a curve in rent-wage-population space, the difference in kinds of amenities suggests that at any given point in time, the future course of the line could depend on the kinds of agglomeration economies generated by the city's growth. Over time, these kinds of agglomeration economies could be affected by random chance, cultural or historical factors, or deliberate government decisions. As the national and global economy changes, relative values of different endogenous amenities might change, affecting the capitalization into wages and rents. Some cities might be left on growth paths that become non-optimal under the new prices. As they cannot go back in time, such changes could require painful transitions in the local economy. From this perspective, it becomes possible to begin asking questions about optimal growth paths in a much more nuanced way.

Whether these broadly drawn suggestions bear more formal fruit remains to be seen. Here we have merely drawn the connection between the line of research using a neoclassical form of regional equilibrium following Roback and the agglomeration literature that has blossomed over the last decade and a half. As the QOL literature rests heavily on the assumption of a neoclassical regional equilibrium, and considering the 
recent importance of the agglomeration literature in both general interest and regional journals, we believe such a connection is crucial in the understanding of local quality of life comparisons and their relevance in a world of increasing returns. Hopefully the agglomeration literature will also benefit from the bridge between the two branches of regional economics.

\section{Conclusion}

This paper has made a minor modification to the compensating differential model formalized by Roback (1982). By allowing for heterogeneous moving costs, the model's output changed considerably. First, the more passive role played by wages when local labor-market equilibrium is assumed stands in contrast to its co-equal status with rent in the original formulation. Second, implications for city population, which had been missing, are drawn out. Third, the vital importance of local land supply comes to the fore. The model is not closed without local land supply, and the interaction between land supply and amenities can be seen as completely determining both rents and wages. Fourth, the theoretical partial derivatives of amenities on rents and wages become ambiguous in sign for all amenity types, which leads us to question their appropriateness as weights in QOL indices when they are derived from hedonic regressions. Fifth, we show that if there is a relationship (either causal or coincidental) between certain amenities and local land supply, QOL indices that use regression coefficients as weights will be biased in favor of areas with high concentrations of supply-reducing amenities. Finally, the inclusion of city size as an output of the model offers a bridge between the 
amenities or quality of life literature and the agglomeration literature that has been so important over the past decade. We consider these all to be significant contributions.

More generally, we consider it an important step in the literature in terms of generating testable hypotheses from the Roback model. The logic behind Roback's original paper was so forceful, and her exposition so clear that we believe that it has been easy to be blinded to the fact that the theory does not actually offer any testable hypotheses, except perhaps that wages and rents differ systematically across cities. Given that, however, any combination of rent and wage coefficients could be rationalized with the model by assuming that the variable in question was either productive or unproductive; an amenity or a disamenity. Roback thus provides us with more of a perspective for interpreting inter-city wage and rent differentials than a theory explaining them.

This paper suffers from many of the same limitations as the Roback paper. For instance, we assume that the city and system of cities is in equilibrium. We assume good information flows exits. The model is not dynamic. Foremost of these shared deficiencies is the fact that it is difficult to imagine a data set that could confirm the existence, for instance, of the supply restriction effect on prices. Any cross-sectional or time-series evidence can be explained by assuming a feature constricting supply is a productive amenity. Nonetheless, we hope that by beginning to force our gaze on alternative explanations and alternative interpretations of the data we can continue the process of assessing the validity of Roback's assumptions. This is an important process because those assumptions determine the validity of the QOL indices based on them, and imply a view of the important determinants of metropolitan prices. We feel our 
assumptions are more realistic. What remains to be seen is whether the practical significance of the differences in results substantially changes our attitudes about such indices or about inter-area price differentials more generally.

\section{References}

Berry, Christopher and Ed Glaeser (2005). "The Divergence of Human Capital Levels Across Cities.” Papers in Regional Science, vol. 84(3): 407-444.

Bloomquist, G.C., M.C. Berger and J.P. Hoehn (1988). "New Estimates of Quality of Life in Urban Areas.” The American Economic Review vol. 78().

Cragg, Michael and Matthew Kahn (1997). "New Estimates of Climate Demand; Evidence from Migration.” Journal of Urban Economics, vol. 42: 261-284.

Duranton, Gilles and Diego Puga (2004). "Micro-foundations of Urban Agglomeration Economies." chp. 48 in Handbook of Regional and Urban Economics, vol. 4, V. Henderson and J.F. Thisse, eds. Amsterdam: North-Holland: 2063-2117.

Glaeser, Edward (1999). “Learning in Cities.” Journal of Urban Economics, vol. 46: 254-277.

Glaeser, Edward and Joseph Gyourko (2005). "Urban Decline and Durable Housing." Journal of Political Economy, vol. 113: 345-375.

Glaeser, Edward, Joseph Gyourko and Ravan Saks (2005). "Why is Manhattan so Expensive?: Regulation and the Rise in House Prices." Journal of Law and Economics, vol. 48(2): 331-370.

Glaeser, Edward, Joseph Gyourko and Ravan Saks (2006). "Urban Growth and Housing Supply.” Journal of Economic Geography vol. 6(1): 71-90.

Glaeser, Edward and David Maré (2001). "Cities and Skills.” Journal of Labor Economics, vol. 19(2): 316-342.

Gyourko, Joseph, Christopher Mayer and Todd Sinai (2006). "Superstar cities." Wharton Real Estate Center Working Paper, June 2006.

Gyourko, Joseph and Albert Saiz (2006). "Construction costs and the supply of housing structure.” Journal of Regional Science, vol 46(4): 661-680. 
Gyourko, Joseph, Matthew Kahn and Joseph Tracy (1999). “Quality of Life and Environmental Comparisons," chp. 37 in vol.3 of in Handbook of Regional and Urban Economics, Edwin S. Mills and Paul Cheshire, eds. Amsterdam: NorthHolland.

Gyourko, Joseph and Joseph Tracy (1991) "The structure of local public finance and the quality of life.” The Journal of Political Economy, vol. 99(4): 774-806.

Helseley, R.W. and W.C. Strange (1990). "Matching and agglomeration economies in a system of cities.” Regional Science and Urban Economics, vol. 20: 189-212.

Kahn, Matthew (1995). “A revealed preference approach for ranking city quality of life.” Journal of Urban Economics, vol. 38: 221-235.

Krugman, Paul (1991). "Increasing Returns and Economic Geography.” The Journal of Political Economy, vol. 99: 483-499.

Krupka, Douglas (2007). "Location-specific Human Capital, Amenity Valuation and Location Choice.” IZA discussion paper number . . . .

Ottaviana, Gianmarco I.P. and Jacques-Francois Thisse (2004). “Agglomeration and economic geography," chp. 58 in Handbook of Regional and Urban Economics, vol. 4, V. Henderson and J.F. Thisse, eds. Amsterdam: North-Holland: 2563-2608.

Roback, Jennifer (1982). “Wages, Rents and the Quality of Life.” The Journal of Political Economy, vol. 90(6): 1257-78.

Rosen, Sherwin (1974). "Hedonic Prices and Implicit Markets: Product differentiation in pure competition.” The Journal of Political Economy, vol. 82(1): 34-55.

Tabuchi, Takatoshi and Jacques-Francois Thisse (2002). “Taste heterogeneity, labor mobility and economic geography.” Journal of Development Economics, vol. 69: 155-177.

Tolley, George S. (1974). “The Welfare Economics of City Bigness.” Journal of Urban Economics, vol 1: 324-345. 
Figure 1: equilibrium in the Roback Model

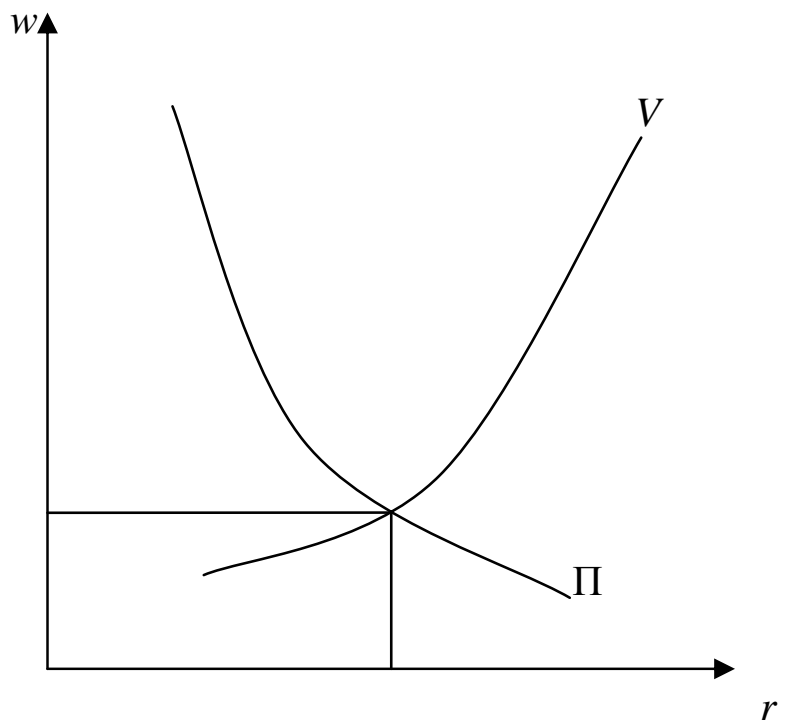

Firgure 2: Effect on wages and rents of a productive amenity

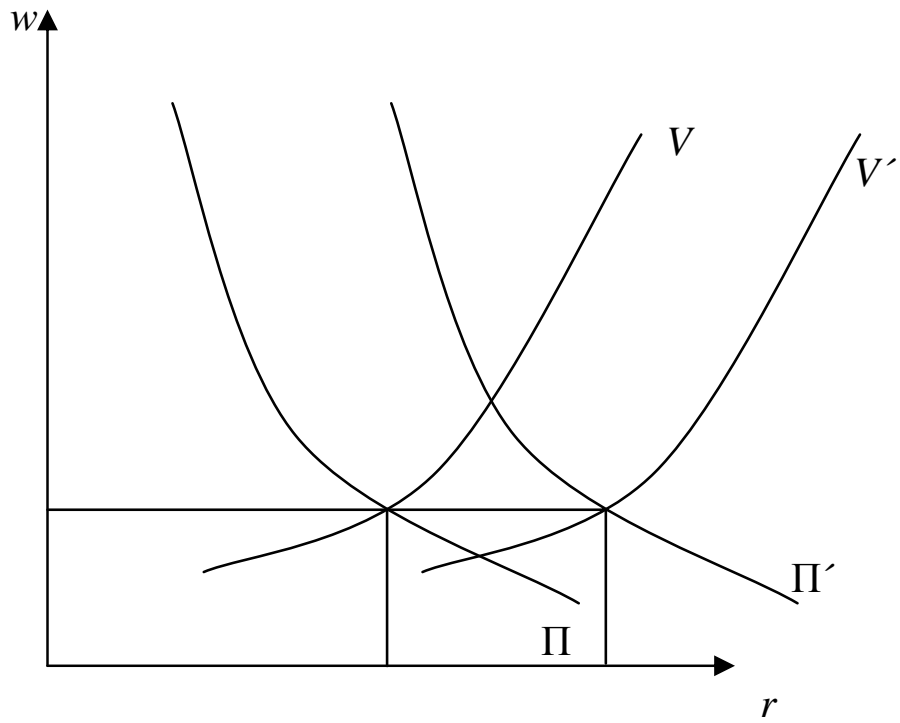


Figure 3: $\Pi$ and $V$ with heterogeneous moving costs
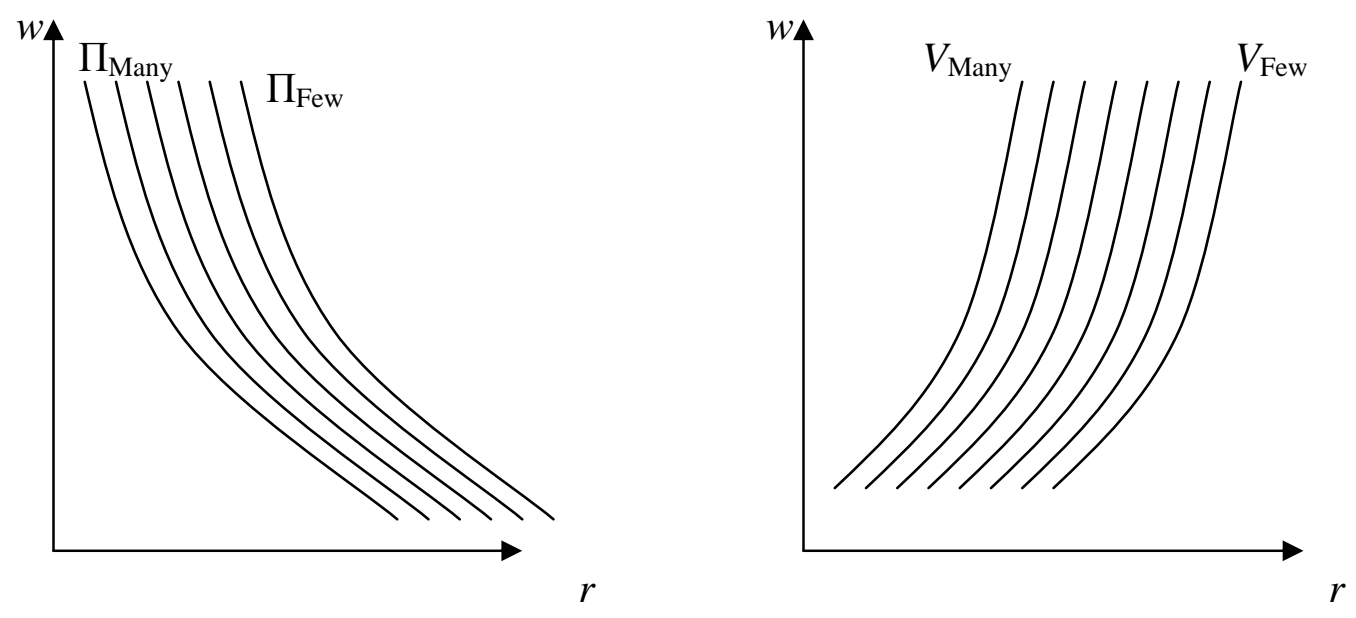

Figure 4: Local labor market equilibirum

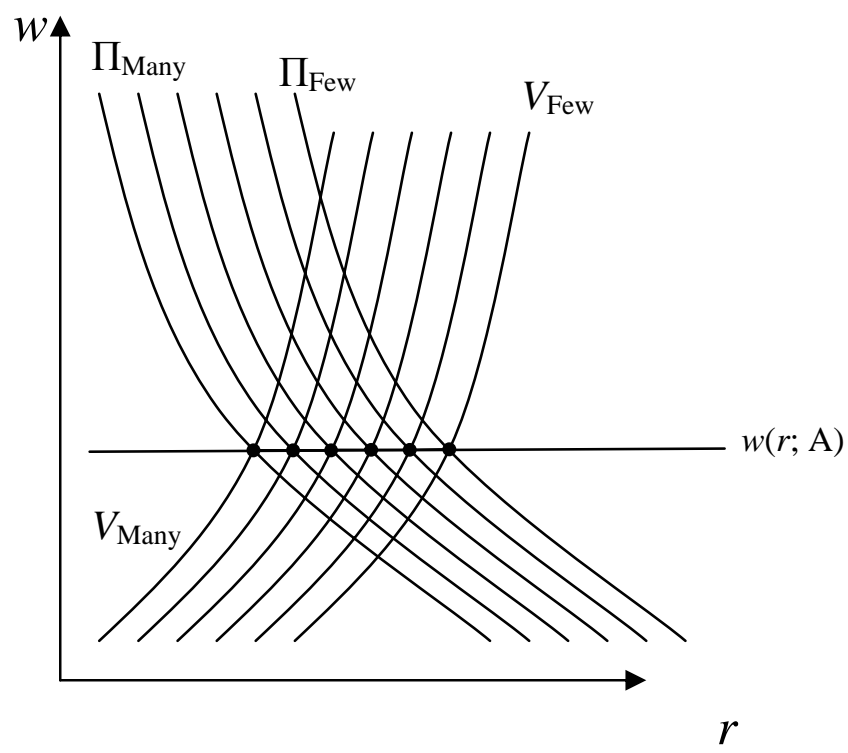

